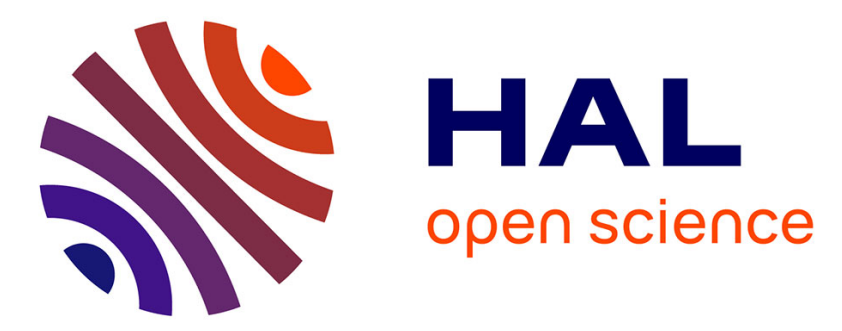

\title{
Direct Synthesis of CF 2 H-Substituted 2-Amidofurans via Copper-Catalyzed Addition of Difluorinated Diazoacetone to Ynamides
}

\author{
Yongxiang Zheng, Anna Perfetto, Davide Luise, Ilaria Ciofini, Laurence \\ Miesch
}

\section{To cite this version:}

Yongxiang Zheng, Anna Perfetto, Davide Luise, Ilaria Ciofini, Laurence Miesch. Direct Synthesis of CF 2 H-Substituted 2-Amidofurans via Copper-Catalyzed Addition of Difluorinated Diazoacetone to Ynamides. Organic Letters, 2021, 23 (14), pp.5528-5532. 10.1021/acs.orglett.1c01876 • hal-03389868

\section{HAL Id: hal-03389868 https://hal.science/hal-03389868}

Submitted on 21 Oct 2021

HAL is a multi-disciplinary open access archive for the deposit and dissemination of scientific research documents, whether they are published or not. The documents may come from teaching and research institutions in France or abroad, or from public or private research centers.
L'archive ouverte pluridisciplinaire HAL, est destinée au dépôt et à la diffusion de documents scientifiques de niveau recherche, publiés ou non, émanant des établissements d'enseignement et de recherche français ou étrangers, des laboratoires publics ou privés. 


\title{
Direct Synthesis of $\mathrm{CF}_{2} \mathrm{H}$-Substituted 2-Amido-Furans via Copper- Catalyzed Addition of Difluorinated Diazoacetone to Ynamides.
}

\author{
Yongxiang Zheng, ${ }^{[a]}$ Anna Perfetto, ${ }^{[b]}$ Davide Luise, ${ }^{[b]}$ Ilaria Ciofini, ${ }^{[b]}$ and Laurence Miesch ${ }^{[a] *}$
}

[a] Equipe Synthèse Organique et Phytochimie, Institut de Chimie, CNRS-UdS, UMR 7177,4 rue Blaise Pascal, CS 90032, 67081 Strasbourg, France

[b] Chimie ParisTech, PSL University, CNRS, Institute of Chemistry for Life and Health Sciences, Chemical Theory and Modelling Group, F-75005 Paris, France

Supporting Information Placeholder
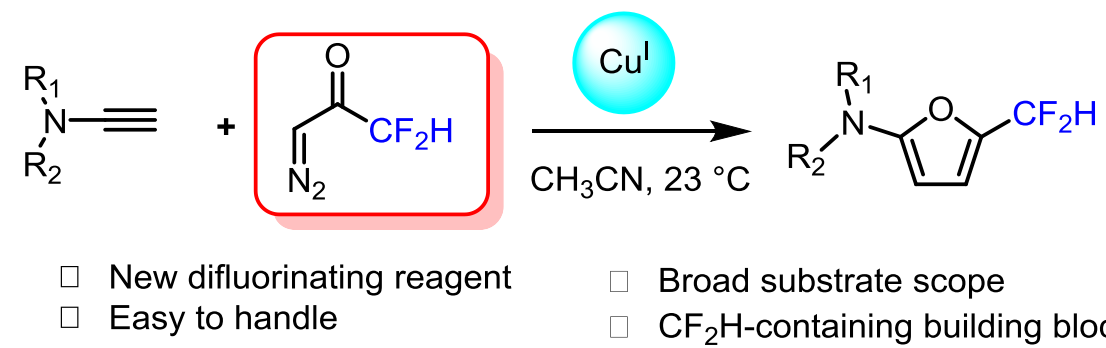

New difluorinating reagent

Broad substrate scope

$\square \mathrm{CF}_{2} \mathrm{H}$-containing building blocks

\begin{abstract}
The significance of molecules containing difluoromethyl groups is driven by their potential applications in pharmaceutical and agrochemical science. Methods for the incorporation of lightly fluorinated groups such as $-\mathrm{CF}_{2} \mathrm{H}$ are less well developed. Here we report the use of difluorinated diazoacetone as a practical reagent for the direct synthesis of $\mathrm{CF}_{2} \mathrm{H}$-substituted 2amido-furans through addition to ynamides. These newly designed difluorinated amidofurans were elaborated to create new nitrogen-containing frameworks that would be challenging to obtain otherwise.
\end{abstract}

The incorporation of fluorine-containing moieties into organic molecules has become a powerful strategy in drug design. ${ }^{[1]}$ Special attention has been paid to the difluoromethyl group $\left(\mathrm{CF}_{2} \mathrm{H}\right)$ because of its unique physicochemical properties. ${ }^{[2]}$ The $\mathrm{CF}_{2} \mathrm{H}$ group can act as an unusual lipophilic hydrogen bond donor and can thereby be considered as a metabolically stable bioisostere of a hydroxyl group or a thiol group. ${ }^{[3]}$ As hydrogen bonding interactions play a crucial role in diverse chemical processes, this surrogate enjoys a special niche in the search for new drug candidates.

Furans represent a privileged structural motif found in myriad natural products, human pharmacopeia, as well as in phytochemistry. $^{[4]}$ Among this family, 2-amino/amidofurans have been identified either as valuable pharmacophores exhibiting significant biological activities, ${ }^{[5]}$ or as building blocks, providing access to a higher degree of molecular complexity. ${ }^{[6]}$ Despite their extensive applicability, only limited protocols have been developed for the synthesis of aminofurans. Classical syntheses involve base-promoted reactions of $\alpha$-hydroxyand halo-ketones with malononitriles. ${ }^{[7]}$ Current methods include transition-metal-catalyzed reactions to construct 2aminofurans with diversified substituents. ${ }^{[8]}$ In this context, Hsung's group investigated a Rh(II)-catalyzed cyclopropenation of ynamides using diazo compounds,
Scheme 1. Synthesis of $\mathrm{CF}_{2} \mathbf{H}$-containing furans.

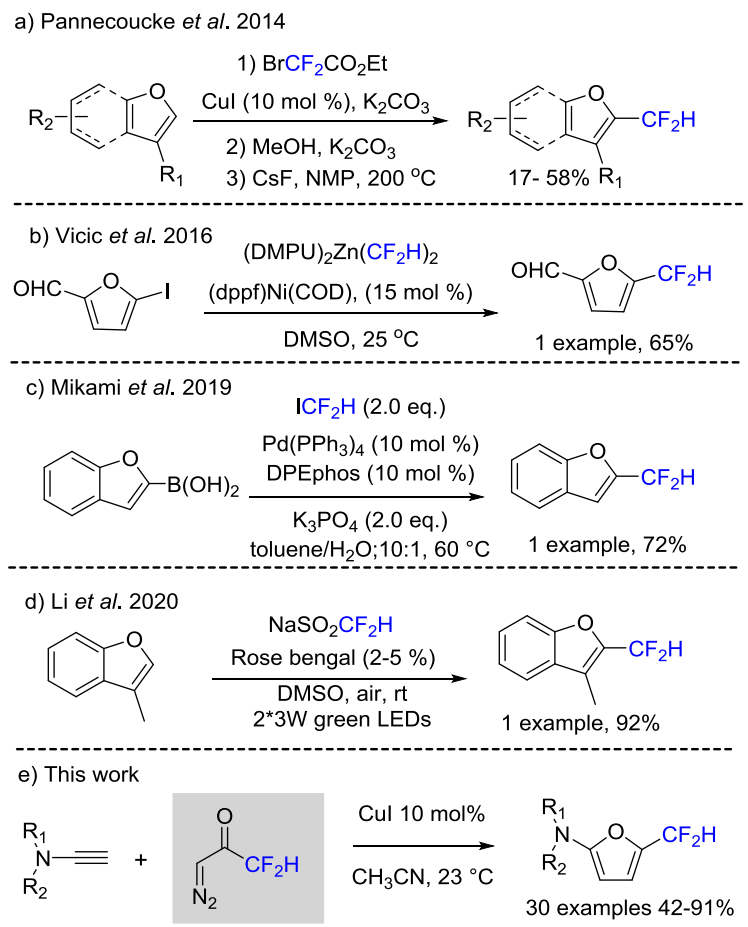


providing an entry to substituted 2-amidofurans. In this process, monosubstituted diazo-carbonyl compounds such as ethyl diazoactetate proved to be ineffective; only dicarbonylated diazo- and iodonium ylides were beneficial. ${ }^{[9]}$

Although the difluoromethylation of heterocycles is in vogue, the synthesis of $\mathrm{CF}_{2} \mathrm{H}$-substituted furans has been scarcely investigated (Scheme 1). Thus, difluoromethylated furans are currently exclusively generated through functionalization of pre-existent furans.

For example, decarboxylation of a $\mathrm{CF}_{2} \mathrm{CO}_{2} \mathrm{Et}$ moiety has been developed to access $\mathrm{CF}_{2} \mathrm{H}$-substituted furans (Scheme 1, a). ${ }^{[10]}$ However, this method requires harsh reaction conditions, which limits functional group compatibility. Among the metalcatalyzed, direct difluoromethylation reactions of heterocycles, only two examples, have been reported to produce $\mathrm{CF}_{2} \mathrm{H}$ substituted furans. Vicic et al. reported a base metal-catalyzed transformation of aryl halides, (Scheme 1, b) ${ }^{[1]}$ whereas Mikami et al. explored a palladium-catalyzed difluoromethylation of arylboronic acids (Scheme1, c). ${ }^{[12]}$ Recently, an elegant direct $\mathrm{CF}_{2} \mathrm{H}$ difluoromethylation of heterocycles via organic photoredox catalysis proved to be efficient on a furan derivative (Scheme $1, \mathrm{~d}){ }^{[13]}$

In view of the limited methods for introduction of the $\mathrm{CF}_{2} \mathrm{H}$ functional group onto the furan substructure, and given our involvement in ynamide chemistry, ${ }^{[14]}$ we envisioned the addition of difluoro-diazoacetone to ynamides (Table 1, e) to provide a convenient entrée to difluoromethylated furans. Among the toolbox of reagents currently utilized to introduce a $\mathrm{CF}_{2} \mathrm{H}$ moiety, the conveniently available $\mathrm{CF}_{2} \mathrm{H}$-diazo-carbonyl compound is conspicuously missing. Taking into account Nikolaev's work, ${ }^{[15]}$ we prepared 3-diazo-1,1-difluoro-propan2-one 3 in a one-step procedure by reacting commercially available 1,1,5,5-tetrafluoropentane-2,4-dione $\mathbf{1}$ in the presence of a diazo-transfer reagent [ $p$-acetamidobenzenesulfonyl azide ( $p$-ABSA)] and DBU. Spontaneous deacylation of the difluorinated diazodiketone $\mathbf{2}$ intermediate took place in the presence of the base, providing the desired difluorodiazoacetone 3 in $58 \%$ yield (Scheme 2).

Scheme 2. Synthesis of difluorodiazoacetone 3.

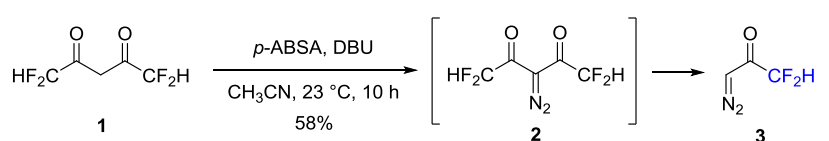

The difluorodiazoacetone reagent was prepared on large scale and is perfectly stable for a few weeks at $4{ }^{\circ} \mathrm{C}$ without any decomposition. Inspired by Fu's work on copper-catalyzed coupling of terminal alkynes with $\alpha$-diazocarbonyl compounds, ${ }^{[16]}$ we hypothesized that ynamides treated with difluoro-diazoacetone in the presence of a copper catalyst would generate amido(difluoromethyl)furans.

To test our hypothesis, we subjected ynamide 4a to difluorodiazoacetone in the presence of diverse copper catalysts. As illustrated in Table 1 , only $\mathrm{CuI}$ and $\mathrm{CuBr}$ proved to be effective (Table 1, entries 1-4), albeit $\mathrm{CuBr}$ led to a huge erosion of the yield $(37 \%)$. Using $\mathrm{Cu}$ (II) catalysts, the starting ynamide 4a underwent degradation in almost all cases (Table 1, entries 5-7), albeit traces of difluoromethylated amidofuran 5a were observed (Table 1, entry 5). The choice of the solvent is criti- cal: use of tetrahydrofuran (THF), dichloroethane (DCE), dioxane, toluene, or ether did not lead to the target molecule (Table 1, entries 8-12), and the starting ynamide was recovered. The use of dimethylformamide led to a significantly lower yield of the desired product (Table 1, entry 13, 27\%). A control experiment using difluoro-diazoacetone without any catalyst afforded none of the desired product (Table 1, entry 14).

Table 1. Screening of solvents and catalysts

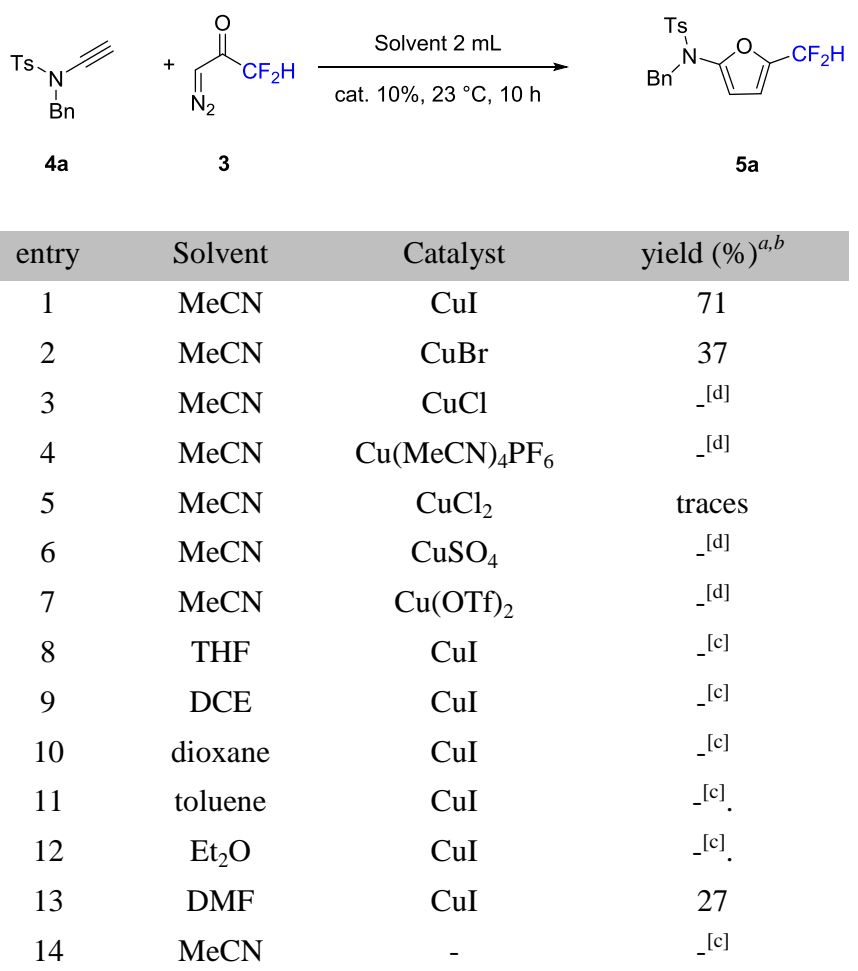

${ }^{a}$ Reaction conditions: to a solution of $4 \mathbf{4 a}(0.2 \mathrm{mmol})$, catalyst (10 mol\%), solvent $(2 \mathrm{~mL}), 3$ (1.5 equiv, $0.5 \mathrm{~mol} / \mathrm{L}$ in $\left.\mathrm{Et}_{2} \mathrm{O}\right)$ was added dropwise at $23{ }^{\circ} \mathrm{C}$. ${ }^{b}$ Isolated yields. ${ }^{c}$ Starting material $4 \mathbf{a}$ was fully recovered. ${ }^{d}$ Degradation was observed.

With the optimized reaction conditions in hand (Table 1, entry 1), we investigated the generality of this transformation. A diverse array of ynamides bearing a variety of functional groups were tested. Linear alkyl groups [e.g., methyl (5b), butyl (5c)] or cyclic alkyl groups [e.g., cyclopropyl (5d), cyclopentyl (5e), or cyclohexyl (5f)] were perfectly accommodated. The reaction is not restricted to saturated substituents; unsaturated side chains with diverse carbon linker chains $\mathbf{5 g}$ $\mathbf{j})$ as well as aryl groups $(\mathbf{5 a}, \mathbf{5} \mathbf{k}, \mathbf{5} \mathbf{l})$ were tolerated as well, albeit the yield of the furan $\mathbf{5 j}$ bearing a terminal alkyne tether is moderate. X-Ray analyses of $\mathbf{5 1}$ confirmed the structure of the amido-difluorinated furan 5l obtained (CCDC 2071668 contains the supplementary crystallographic data for the structure). ${ }^{[17]}$ Notably, even halogens $(\mathbf{5 m})$, nitriles $(\mathbf{5 n})$, protected aldehydes (5o), ketones (5p), and amides (5q, 5r) could be used, significantly broadening the substrate scope and providing the corresponding difluorinated furans with good yields. 
Scheme 3. Scope of the synthesis of amido-difluorinated furans regarding the ynamide.

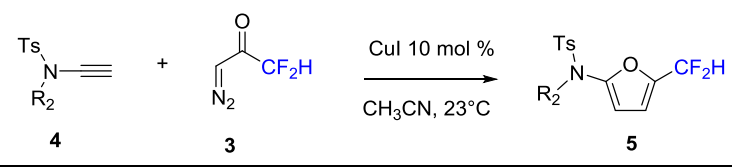

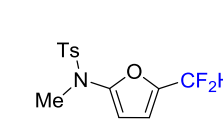

5b, $79 \%$

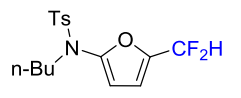

$5 c, 74 \%$

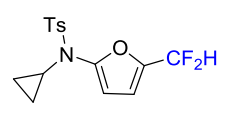

5d, $78 \%$

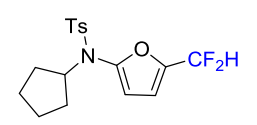

5 e, $85 \%$

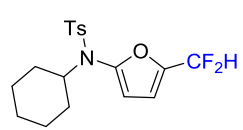

5f, $71 \%$

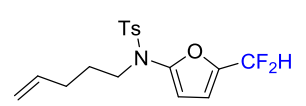

5g, $82 \%$

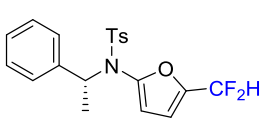

5k, $80 \%$

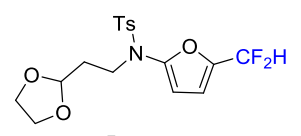

5o, $74 \%$

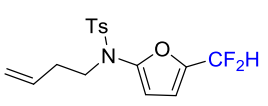

5h, $63 \%^{a}$

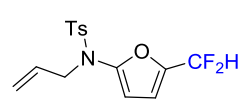

5i, $85 \%$

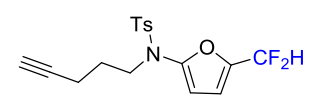

5j, $42 \%$

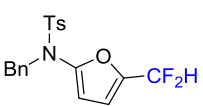

5a, $71 \%^{a}$

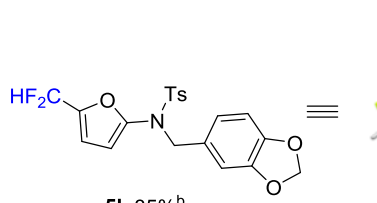

5I, $85 \%^{\mathrm{b}}$
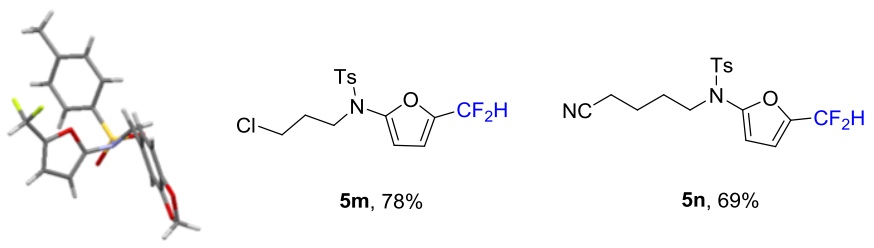

$5 \mathrm{~m}, 78 \%$

5n, $69 \%$

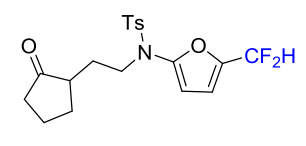

5p, $51 \%^{\mathrm{c}}$

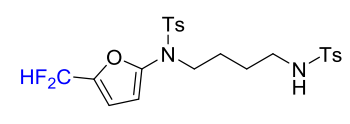

5q, $79 \%$

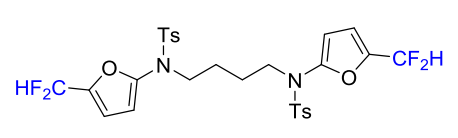

$5 r, 68 \%$

${ }^{\text {a }}$ Performed on 0.4 mmole scale; ${ }^{b}$ See [17] for CCDC deposition number; ${ }^{c}$ yield of the two-step process: deprotection of the ynamide and

cyclization

The influence of the electron-withdrawing group on the nitrogen atom was also explored (Scheme 4). Furans bearing an oxazolidinone (7a, 7b) and amide moiety (7c) were obtained in modest yields. Sulfonyl groups such as mesyl (7d), nosyl (7e), and trimethyl-/triisopropyl-/trifluoromethylbenzenesulfonamides $(\mathbf{7 g}, \mathbf{7 h}, \mathbf{7 i})$ were revealed to be accommodated in this transformation. More hindered cyclic sulfonamides were notably effective, providing the corresponding furans $(\mathbf{7 j}, \mathbf{7 k}, \mathbf{7 l})$ in good yields. A sulfamoyl derivative was also incorporated, providing furan $7 \mathbf{f}$ in $70 \%$ yield.

To demonstrate the diversification potential of these difluorinated furans, we used them as building blocks to prepare various relevant heterocycles. Nitration ${ }^{(18)}$ of amidodifluorinated furan 71 under controlled temperature led exclusively to C-4 nitrofuran 8 (Scheme 5, a). Further, we involved the amidofurans as platforms in intramolecular oxidative coupling reactions ${ }^{(19)}$ as well as in intramolecular Diels-Alder cycloadditions (IMDAF). ${ }^{(20)}$ The oxidation process on compound $5 \mathbf{i}$ took place in the presence of a catalytic amount of $\mathrm{PdCl}_{2}\left(\mathrm{MeCN}_{2}, \mathrm{CuCl}_{2}\right.$, and the environmentally sustainable reoxidant $\mathrm{O}_{2}$ to provide difluorinated furo[2,3-b]pyrrole 9 in a yield of $83 \%$ (Scheme 5, b). Whereas direct difluorination will only provide 2 -substituted indolines, ${ }^{[13]}$ intramolecular Diels Alder reaction of amido-furans $\mathbf{5 h}$ led to difluorinated indoline 10 bearing a $\mathrm{CF}_{2} \mathrm{H}$ group at position 5 that would be challenging to obtain otherwise (Scheme 5, c).
Scheme 4. Modification of the electron-withdrawing group on the nitrogen

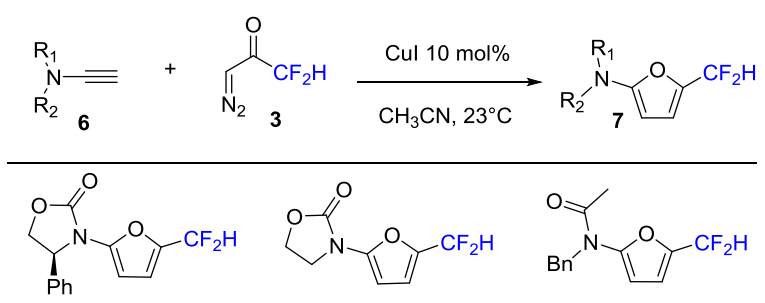

$7 a, 67 \%$

$7 b, 42 \%$

$7 c, 57 \%$
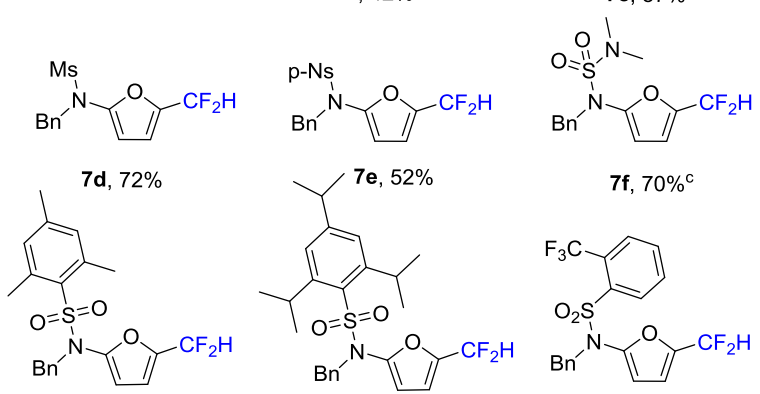

7f, $70 \%{ }^{\mathrm{c}}$

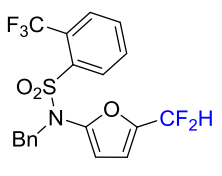

$7 \mathbf{g}, 68 \%$
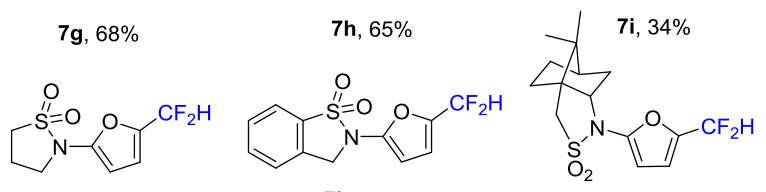

$7 \mathbf{j}, 70 \%{ }^{\mathrm{c}}$

$\mathbf{7 k}, 81 \%$

7I, $91 \%$

c yield of the two-step process: deprotection of the ynamide and cyclization. 
Scheme 5. Synthetic applications of difluorinated furans

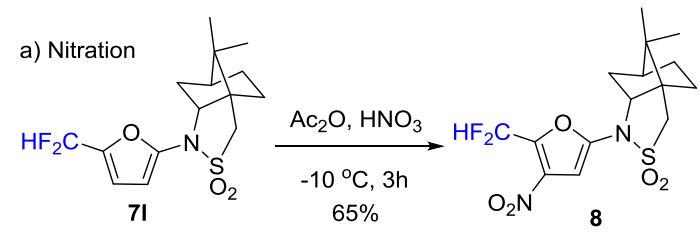

b) Intramolecular oxidative coupling reaction
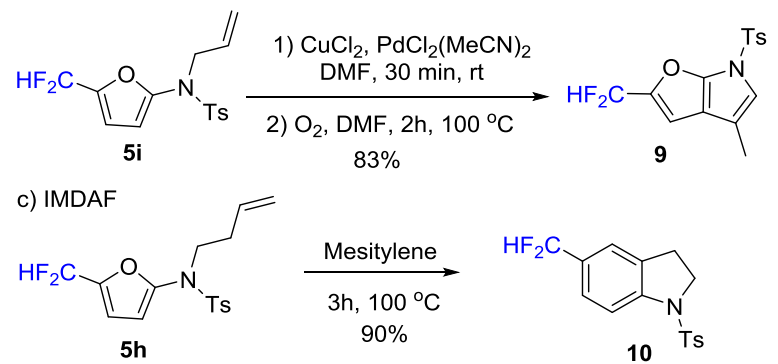

Based on deuterium incorporation experiments, literature data and on DFT calculations (see supporting information for more details), we propose the following mechanism (Scheme 6). In the presence of copper(I) salt, ynamide A leads to copperynamidyl B. The reaction of the latter with difluorodiazoacetone forms copper specie $\mathbf{C}$. Rearrangement and loss of $\mathrm{N}_{2}$ leads to copper intermediate $\mathbf{D}{ }^{(21)}$ At this point, two reactions pathways were envisioned: Protonation $\alpha$ to the carbonyl moiety leading to a Fu type compound $\mathbf{E}^{(16)}$ or protonation $\gamma$ to the carbonyl moiety providing intermediate $\mathbf{G}$. Both pathways were examined by DFT based calculations and have been found to be kinetically and thermodynamically possible (see Supporting Information for detailed description). $O$-alkylation on ynamide $\mathbf{E}$ or allenamide $\mathbf{G}$ followed by rearomatization of $\mathbf{F}$ and $\mathbf{H}$ and decupration of $\mathbf{I}$ regenerates the copper iodide and forms the difluoromethylated amidofuran $\mathbf{J}$. These proposed reaction mechanisms are in agreement with the deuterium incorporation experiments. Dincorporation $\alpha$ to the carbonyl moiety (D position 4 of the furan) followed by decupration (D-position 3) (pathway D-EF) or D-incorporation $\alpha$ to difluoroacetone (D position 4) followed by decupration (D-position 3) will lead to equal incorporation of deuterium at position 3 and 4 as observed experimentally.

\section{Scheme 6. Plausible Mechanism}

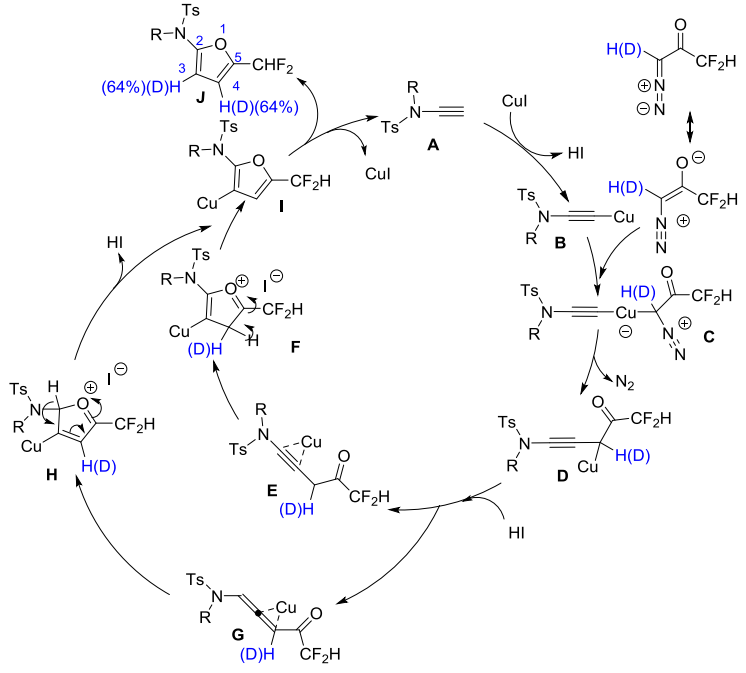

In conclusion, we have developed a copper-catalyzed synthesis of difluomethylated amidofurans through addition of difluorodiazoacetone to ynamides. Difluorodiazoacetone was prepared for the first time, and proved to be the ideal candidate to perform this transformation. The method exhibits broad functional group tolerance and led to a number of highly diverse, high-value scaffolds. Finally, it was demonstrated that these newly designed difluoromethylated amidofurans could serve as platforms to construct a diverse set of more complex difluorinated heterocyclic molecules valuable for drug design.

\section{ASSOCIATED CONTENT}

\section{Supporting Information}

The Supporting Information is available free of charge on the ACS Publications website.

Supporting information (PDF)

CCDC 2071668 contain the supplementary crystallographic data for this paper. These data can be obtained free of charge via www.ccdc.cam.ac.uk/data_request/cif, or by emailing data_request@ccdc.cam.ac.uk, or by contacting The Cambridge Crystallographic Data Centre, 12 Union Road, Cambridge CB2 1EZ, UK; fax: +44 1223336033.

\section{AUTHOR INFORMATION}

\section{Corresponding Author}

*1miesch@unistra.fr

\section{ACKNOWLEDGMENT}

Support for this work was provided by CNRS and Université de Strasbourg. Y.Z thanks CSC for a research fellowship. The authors thank Dr. Catherine Gaulon-Nourry from the Institut des Molécules et Matériaux du Mans, IMMM UMR 6283 CNRS-Le Mans Université for fruitful discussions. 
[1]

(a) Bégué, J.-P.; Bonnet-Delpon, D. Bioorganic and Medicinal Chemistry of Fluorine, Wiley, Hoboken, 2008. (b) Hagmann, W. $\mathrm{K}$. The many roles for fluorine in medicinal chemistry. J. Med. Chem. 2008, 51, 4359-4369. (c) Kirsch, P. Modern Fluoroorganic Chemistry: Synthesis Reactivity, Applications 2nd Ed. (Wiley-VCH, Weinheim, 2013).

[2] For recent reviews on difluoromethylation reactions see: (a) $\mathrm{Hu}$, J.; Zhang, W.;Wang, F. Selective Difluoromethylation and Monofluoromethylation reactions. Chem. Commun. 2009, 7465-7478. (b) Ichikawa, J. Synthetic Methods for Heterocycles and Carbocycles Bearing Fluorinated One-Carbon Units $\left(=\mathrm{CF}_{2}, \mathrm{CHF}_{2}\right.$, or $\left.\mathrm{CF}_{3}\right)$ : Intramolecular Reaction of 2-Trifluoromethyl-1- alkenes J. Synth. Org. Chem. Jpn. 2010, 68, 1175 - 1184. (c) Lu, Y.; Liu, C.; Chen, Q.Y. Recent Advances in Difluoromethylation Reaction. Curr. Org. Chem. 2015, 19, 1638-1650. (d) Belhomme, M.-C.; Besset, T.; Poisson, T.; Pannecoucke, X. Recent Progress toward the Introduction of Functionalized Difluoromethylated Building Blocks onto $\mathrm{C}\left(\mathrm{sp}^{2}\right)$ and C(sp) Centers. Chem. Eur. J. 2015, 21, 12836-12865. (e) Yerien, D. E.; Barata-Vallejo, S.; Postigo, A. Difluoromethylation Reactions of Organic compounds. Chem. Eur.J. 2017, 23, 14676-14701. (f) Carbonnel, E.; Poisson, T.; Jubault, P.; Pannecoucke, X.; Besset, T. Recent Advances for Direct Introduction of the $\mathrm{CF}_{2} \mathrm{Me}$ Moiety. Front. Chem. 2019, 7, 1-11. (g) Lemos, A.; Lemaire, C.; Luxen, A. Progress in Difluoroalkylation of Organic Substrates by Visible Light Photoredox Catalysis. Adv. Synth. Catal. 2019, 361, 1500-1537. (h) $\mathrm{Hu}$, J.; Xie, Q. Chen's Reagent A Versatile Reagent for Trifluoromethylation, Difluoromethylenation, and Difluoroalkylation in Organic Synthesis. Chin. J. Chem. 2020, 38, 202-212. (i) Sap, J. B. I.; Meyer, C. F.; Straathof, N. J. W.; Iwumene, N.; am Ende, C. W.; Trabanco, A. A.; Gouverneur, V. Late-stage difluoromethylation: concepts, developments and perspective. Chem. Soc. Rev., 2021, DOI: $10.1039 / \mathrm{d} 1 \mathrm{cs} 00360 \mathrm{~g}$.

[3] (a) Sessler, C. D.; Rahm, M.; Becker, S.; Goldberg, J. M., Wang, F.; Lippard, S. J. $\mathrm{CF}_{2} \mathrm{H}$, a Hydrogen Bond Donor. J. Am. Chem. Soc. 2017, 139, 9325-9332. (b) Zafrani, Y. ; Sod-Moriah, G. ; Yeffet, D.; Berliner, A.; Amir, D.; Marciano, D.; Elias, S.; Katalan, S.; Ashkenazi, N.; Madmon, M.; Gershonov, E.; Saphier, S. $\mathrm{CF}_{2} \mathrm{H}$, a Functional Group-Dependent Hydrogen-Bond Donor: Is It a More or Less Lipophilic Bioisostere of $\mathrm{OH}, \mathrm{SH}$, and $\mathrm{CH}_{3}$ ? J. Med. Chem. 2019, 62, 5628-5638.

[4] (a) Katritzky, A. R. Comprehensive Heterocyclic Chemistry III, Elsevier, Amsterdam, New York, 1st Ed., 2008. (b) Gulevich, A. V.; Dudnik, A. S.;Chernyak, N.;Gevorgyan, V. Transition MetalMediated Synthesis of Monocyclic Aromatic Heterocycles. Chem. Rev. 2013, 113, 3084-3213. (c) Yeung, K.-S.; Peng, X.-S.; Wu, J.; Fan, R.; Hou, X.-L. Chapter 4.3-Five-Membered Ring Systems: Furans and Benzofurans. Prog. Heterocycl. Chem. 2013, 25, 183-215.

[5] Harris, P. A.; Bandyopadhyay, D.; Berger, S. B.; Campobasso, N.; Capriotti, A.; Cox, J. A.;Dare, L.;Finger, J. N.;Hoffman, S. J.;Kahler, K. M.;Lehr, R.;Lich, J. D.;Nagille, R.; Nolte, R. T.; Ouellette, M. T.;Pao, C. S.; Schaeffer, M. C.; Smammwood, A.; Sun, H. H.; Swift, B. A.; Totoritis, R. D.; Ward, P.; Marquis, R. W.; Bertin, J.; Gough, P. J. Discovery of Small Molecule RIP1 Kinase Inhibitors for the treatment of Pathologies Associated with Necroptosis. ACS Med. Chem. Lett. 2013, 4, 1238-1243.

[6] (a) Nicolaou, K. C.; Baran, P. S.; Zhong, Y.-L.; Fong, K. C.; H.-S. Choi, Total Synthesis of (CP-Molecules (CP-263, 114 and CP-225, 917, Phomoidrides B and A). 2. Model Studies for the Construction of Key Structural Elements and First-Generation Strategy. J. Am. Chem. Soc. 2002, 124, 2190-2201. (b) Trost, B. M.; McDougall, P. J. Access to a Welwitindoline Core Using Sequential Cycloadditions. Org. Lett. 2009, 11, 3782-3785. (c) Wipf, P.; Petronijevic, F. R. Total Synthesis of (+)-Cycloclavine and (+)-5-epiCycloclavine. J. Am. Chem. Soc. 2011, 133, 7704-7707.

[7] Classical syntheses of amino/amido furans see: (a) Gewald, K. Uber die Reaktion von $\alpha$-Hydroxy-ketonen mit Malodinitril. Chem. Ber. 1966, 99, 1002-1007. (b) Kato, T.; Kimura, H.; Tanji, K. Reaction of Ethyl 4-Halo-3-oxobutanoate with Diethyl Malonate, Methyl Cyanoacetate, and Molononitrile. Chem. Pharm. Bull. 1978, 26, 3880-3883.
[8] For selected Metal-catalyzed syntheses of amino/amido furans see: (a) Murai, M.; Koji, M.; Ohe, K. A New Route to 3-Acyl2Aminobenzofurans: Palladium-Catalyzed Cycloisomerization of 2 (Cyanomethyl)phenyl Esters. Chem. Commun. 2009, 3466-3468. (b) Murai, M.;Yoshida, S.; Koji, M.; Kouichi, O. Atom-efficient synthesis of $\alpha$-Alkylidene- $N$-Furylimines via Catalytic Vinyl-CarbeneTransfer Reactions to Carbonyl-Ene-Nitrile Compounds. Chem. Commun. 2010, 46, 3366-3368. (c) Dateer, R. B.; Pati, K.; Liu, R.-S. Gold-Catalyzed Synthesis of Substituted 2-Aminofurans via Formal [4+1]-Cycloadditions on 3-en-1-Ynamides. Chem. Commun. 2012, 48, 7200-7202. (d) Jiang, Y.; Khong, V. Z. Y.; Lourdusamy, E.; Park, C.-M. Synthesis of 2-Aminofurans and 2-unsubstituted Furans via Carbenoid-Mediated [3+2] Cycloaddition. Chem Commun. 2012, 48, 3133-3135. (e) Wang, S.; Ni, Z.; Huang, X.; Wang, J.; Pan, Y. Copper-Catalyzed Direct Amidation of Heterocycles with $\mathrm{N}$ Fluorobenzenesulfonimide. Org. Lett. 2014, 16, 5648-5651. (f) Cheng, C.; Liu, S.; Zhu, G. Palladium-Catalyzed Cycloisomerization and Aerobic Oxidative Cycloisomerization of Homoallenyl Amides: A Facile and Divergent Approach to 2-AminoFurans. Org Lett. 2015, 17, 1581-1584. (g) Ye, W.; Tan, C.; Yao, J.; Xue, S.; Li, Y.; Wang, C. Iodine-Promoted Domino Reactions of 1-Cyanocyclopropane 1Esters: A Straightforward Approach to Fully Substituted 2Aminofurans. Adv. Synth. Catal. 2016, 358, 426-434. (h) Kondoh, A.; Ishikawa, S.; Aoki, T.; Terada, M. Synthesis of 2,3-allenylamides utilizing [1,2]-phospha-Brook Rearrangement and their application to gold-catalyzed cycloisomerization providing 2-aminofuran derivatives. Chem. Commun. 2016, 52, 12513-12516. (i) Shoji, T.; Nagai, D.; Araki, T.; Ohta, A.; Sekiguchi, R.; Ito, S. Mori, S.; Okujima, T. Synthesis of 2-Aminofurans by Sequential $[2+2]$ CycloadditionNucleophilic Addition of 2-Propyn-1-ols with Tetracyanoethylene and Amine-Induced Transformation into 6-Aminopentafulvenes Chem. Eur. J. 2017, 23, 5126-5136. (j) Wang, L.-C.; Geng, H.-Q.; Peng, J.-B.; Wu, X.-F. Iron-Catalyzed Synthesis of 2-Aminofurans from 2-Haloketones and Tertiary Amines or Enamines. Eur. J. Org. Chem. 2020, 2605-2616.

[9] Hsung, R. P.; Li, H. Highly Substituted 2-Amido-furans From Rh(II)-Catalyzed Cyclopropenations of Ynamides. Org. Lett. 2009, 11, 4462-4465.

[10] Belhomme, M.-C.; Poisson, T.; Pannecoucke, X. CopperCatalyzed Direct C-2 Difluoromethylation of Furans and Benzofurans: Access to $\mathrm{C}-2 \mathrm{CF}_{2} \mathrm{H}$ derivatives. J. Org. Chem. 2014, 79, 7205-7211.

[11] Xu, L.; Vicic, D. A. Direct Difluoromethylation of Aryl Halides via Base Metal Catalysis at Room Temperature. J. Am. Chem. Soc. 2016, 138, 2536-2539.

[12] Hori, K.; Motohashi, H.; Saito, D.; Mikami, K. Precatalyst Effects on Pd-Catalyzed Cross-coupling Difluoromethylation of Aryl Boronic Acids. ACS Catal. 2019, 9, 417-421.

[13] Zhang, W.; X.-X.; Chen, J.; Yang, C.; Pan, Y.-L.; Cheng, J.-P.; Meng, Q.; Li, X. Direct C-H Difluoromethylation of Heterocycles via Organic Photoredox Catalysis. Nature Communications 2020, 11, 1-10.

[14] (a) Heinrich, C.F.; Fabre, I.; Miesch, L. Silver Catalyzed $7-$ exo-dig Cyclization of Silylenolether-ynesulfonamides, Angew. Chem. Int. Ed. 2016, 55, 5170-5174. (b) Zheng, Y.-X; Andna, L.; Bistri, O.; Miesch, L. Tertiary Enamide-promoted Diastereoselective Domino: N-Acyliminium Ion Trapping and Nazarov Cyclization. Org. Lett. 2020, 22, 6771-6775.

[15] Zakharova, V. M.; Hennig, L.; Nikolaev, V. A. Wittig Reaction of a series of Diazodiketones: Synthesis and Structure of Fluorine-Containing Vinyldiazoketones. Synthesis 2005, 2871-2874.

[16] Suarez, A.; Fu, G. C. A Straightforward and Mild Synthesis of Functionalized 3-Alkynoates. Angew. Chem. Int. Ed. 2004, 43, 3580-3582.

[17] CCDC 2071668 (3m) contains the supplementary crystallographic data for this paper. These data can be obtained free of charge from The Cambridge Crystallographic Data Centre.

[18] Bianco, A.; Brufani, M.; Dri, D. A.; Melchioni, C.; Filocamo, L. Design and Synthesis of a New Furanosic Sialylmimetic as a potential Influenza Neuraminidase Viral Inhibitor. Lett. Org. Chem., 2005, 2, 83-88. 
[19] Beccalli, E. M.; Borsini, E.; Broggini, G.; Rigamonti, M.; Sottocornola, S. Intramolecular Palladium-Catalyzed Oxidative Coupling on Thiophene and Furan Rings: Determinant Role of Electronic Availability of the Heterocycle. Synlett 2008, 1053-1057.

[20] Flick, A. C.; Pawda, A. Intramolecular Diels-Alder Cycloaddition of Furans (IMDAF) for Natural Product Synthesis. Advances in Heterocyclic Chemistry, 2013, 110, 1-41.
[21] Xiao, Q.; Xia, Y.; Li, H.; Zhang, Y.; Wang, J. Coupling of N-Tosylhydrazones with Terminal Alkynes Catalyzed by Copper(I): Synthesis of Trisubstituted Allenes. Angew. Chem. Int. Ed. 2011, 50, 1114-1117. 